\title{
A Novel Mutation of the Menin Gene in a Family with Jultijple Endocrine Neoplasia Type 1
}

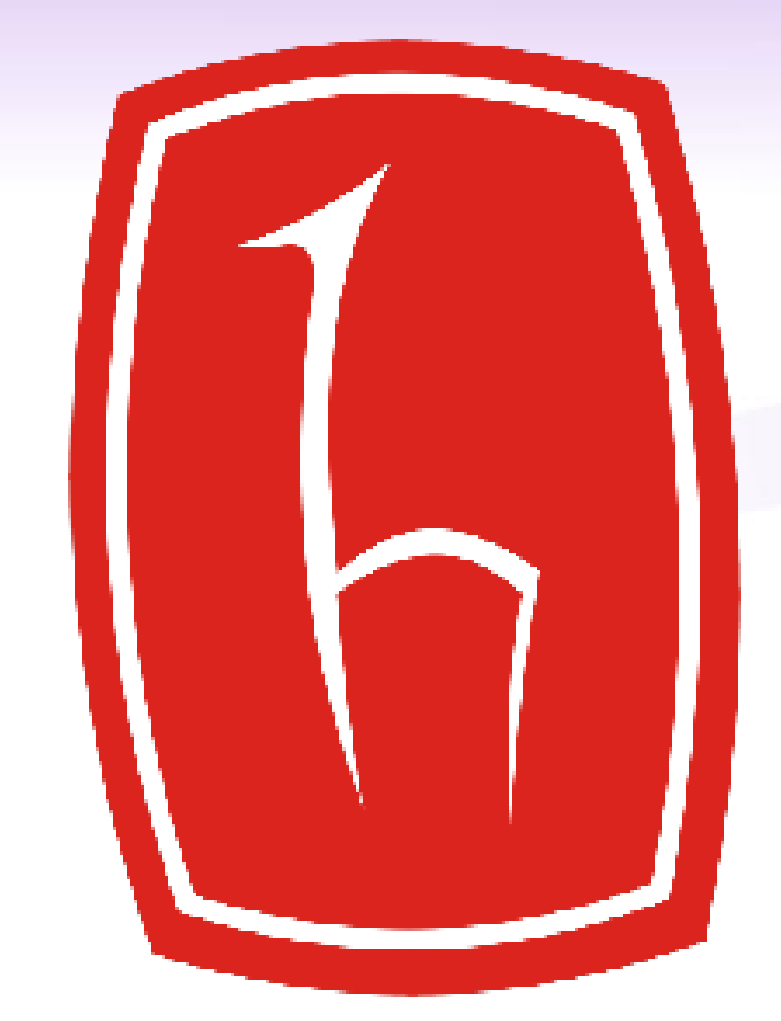

\author{
Suleyman Nahit Sendur, Ahmet Dogrul, Serkan Kabacam, Osman Abbasoglu, Sevgen Onder, \\ Cenk Sokmensuer, Belkis Erbas, Selcuk Dagdelen, Mehmet Alikasifoglu, Tomris Erbas
}

Hacettepe University Medical School, Ankara, Turkey

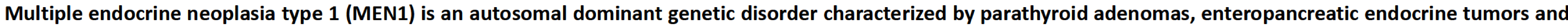

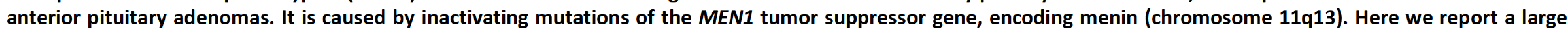
family with a novel heterozygous mutation of the menin gene.

\section{Case 1}

The index male patient (42-year-old) presented with symptoms of hypoglycemia. During fasting state, low glucose level $(51 \mathrm{mg} / \mathrm{dL})$ and inappropriately high plasma insulin level $(9.1 \mu \mathrm{U} / \mathrm{ml})$ were documented. Abdominal MRI revealed $24 \mathrm{~mm}$ lesion in the tail of the pancreas. He underwent a distal pancreatectomy and splenectomy. Histology confirmed pancreatic neuroendocrine tumor (glucagon, synaptophysin and chromogranin were positive on immunostaining, but insulin was negative). He has biochemical evidence of primary hyperparathyroidism (Ca: $11.6 \mathrm{mg} / \mathrm{dL}, \mathrm{P}: 2.5 \mathrm{mg} / \mathrm{dL}$ and PTH: $178 \mathrm{pg} / \mathrm{mL}$ ). 99mTc-MIBI scintigraphy revealed increased focal radiotracer retention in right thyroidal bed. The patient underwent a single-gland parathyroidectomy. Six months later, he required further neck expolaration for recurrence of parathyroid adenoma. His remaining 3 parathyroid glands were resected and histology confirmed parathyroid hyperplasia. His pituitary MRI and pituitary hormone levels were within normal limits.

Genetic analysis identified a novel mutation on chromosome 11q13.1 which was c.218insGGCGGCAC heterozygote.

\section{Case 2}

A 21-year-old male patient, after his father's diagnosis of MEN 1 with genetic confirmation, screened for MEN 1. Pituitary hormone profile and pituitary MRI were normal. Further investigations showed hypercalcemia (Ca: $10.6 \mathrm{mg} / \mathrm{dL}$ ), with raised parathyroid hormone, $134 \mathrm{pg} / \mathrm{mL}$ (n: 12-88). Parathyroid ultrasonography confirmed two suspicious parathyroid adenomas for which he underwent four-gland parathyroidectomy and thymectomy. Histopathological examination confirmed parathyroid hyperplasia. Abdomen CT revealed two pancreatic lesions ( $10 \mathrm{~mm}$ at uncinate process and $5 \mathrm{~mm}$ at tail of the pancreas) with normal serial fasting gut peptides and chromogranin A $(31.9 \mathrm{ng} / \mathrm{mL})$. Additionally, he had no signs or symptoms suggesting a pancreatic involvement. He continued to attend for regular biochemical and image re-evaluation.

\section{Case 3}

She (45-year-old) is the sister of index case. Her laboratory tests showed hypercalcemia $(10.3 \mathrm{mg} / \mathrm{dL})$, hypophosphatemia $(2.1 \mathrm{mg} / \mathrm{dL})$ and elevated serum PTH (327 pg/mL) levels. 99mTc-MIBI scintigraphy revealed increased radiotracer retention in the left side. Parathyroid ultrasonography showed 36 $\mathrm{mm}$ parathyroid adenoma. She underwent parathyroidectomy, postoperatively she remains with normal calcium and parathyroid hormone levels. Histopathology confirmed parathyroid hyperplasia. During investigation of her hyperparathyroidism, pituitary MRI had demonstrated a $3.5 \times 5.5 \mathrm{~mm}$ pituitary microadenoma with normal pituitary hormones. Adrenal CT showed minimal nodular hyperplasia at left adrenal gland, however, she has not presented any clinical symptoms. Her adrenal function test were normal. Pancreas BT showed no evidence of a tumour. Her biochemical and imaging monitoring are continuing on a regular basis.

\section{Case 4}

She (50-year-old) is the other sister of index case. Laboratory tests revealed elevated calcium $11.9 \mathrm{mg} / \mathrm{dL}$ with elevated PTH $441 \mathrm{pg} / \mathrm{mL}$. Parathyroid ultrasonography confirmed parathyroid adenoma $(26 \times 16 \mathrm{~mm})$ in the left. She underwent a total parathyroidectomy and timectomy, which resulted in a normalization of serum calcium and parathyroid hormone levels. Histology confirmed parathyroid hyperplasia. Baseline pituitary hormone profile was normal except for minimal raised prolactin level, $43 \mathrm{pg} / \mathrm{mL}$. Pituitary MRI indicated a macroadenoma with right cavernous sinus extension.

Chromogranin A level was found to be elevated $(223 \mathrm{ng} / \mathrm{mL})$ and a multiple pancreatic tumors (two lesions in the body of the pancreas and one in the tail) were identified in the somatostatin receptor PET/CT imaging with Ga-68 DOTATATE. She did not accepted further surgical treatment for pancreatic lesions. Serial follow-up imaging of pancreas showed stable appearances. She has also hormonally inactive, bilateral adrenal nodular hyperplasia.

\section{Case 5}

He (27-year-old) is the son of case 4. Clinical studies in the patient showed elevated serum calcium $(11.4 \mathrm{mg} / \mathrm{dL})$ and low serum phosphate $(1.7 \mathrm{mg} / \mathrm{dL})$ and increased parathyroid hormone concentration $(136 \mathrm{pg} / \mathrm{mL})$. Parathyroid ultrasonography revealed $8 \times 6 \mathrm{~mm}$ lesion in the left inferior position suggestive of parathyroid adenoma. The patient underwent parathyroidectomy and thymectomy. Histopathological examination confirmed parathyroid hyperplasia. Adrenal CT showed minimal nodular hyperplasia at left adrenal gland. His adrenal function tests were normal. Abdomen $\mathrm{CT}$ revealed one pancreatic lesion (19x21 $\mathrm{mm}$ at body of the pancreas) with normal chromogranin A $(62 \mathrm{ng} / \mathrm{mL})$. The pancreatic lesion was Ga-68 DOTATATE-avid. Additionally, he had no signs or symptoms suggesting a pituitary involvement and MRI pituitary was normal. $\mathrm{He}$ is waiting for pancreas surgery for pancreatic lesion.

\section{Case 6}

\section{She (24-year-old) is the daughter of case 4.}

She presented asymptomatic hypercalcemia $(11.1 \mathrm{mg} / \mathrm{dL})$ and markedly raised serum PTH (198 mg/dL). 99mTc-MIBI scintigraphy and ultrasonography revealed increased radiotracer retention in the left inferior $(10 \times 6 \mathrm{~mm})$ and right superio $(13 \times 8 \mathrm{~mm})$ parathyroids suggestive of parathyroid adenomas. Neck exploration revealed a parathyroid lesions which were successfully removed. Histopathological examination confirmed parathyroid hyperplasia. Despite invitro fertilization methods, she was unable to conceive. After parathyroid surgery, she became pregnant spontaneously. Pancreas CT showed no evidence of a neuroendocrine tumor. Additionally, the patient had no signs or symptoms suggesting a pituitary or adrenal involvement.

We conclude that multiple endocrine neoplasia type 1 in this family was associated with a novel c.218insGGCGGCAC heterozygote mutation of the menin gene. Genetic analysis of menin gene facilitates clinical management and provides benefits to patients and their families with MEN1.
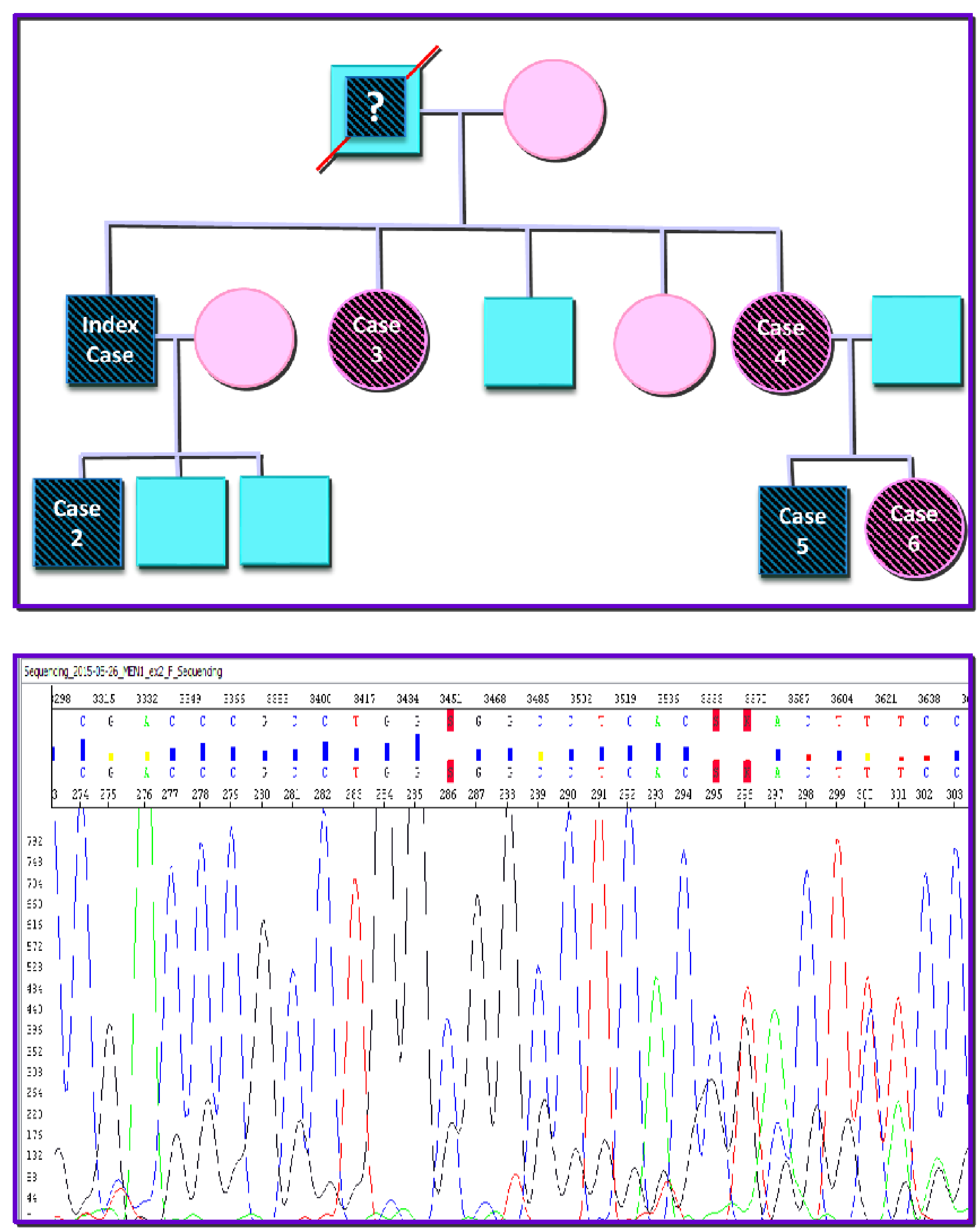

c.218insGGCGGCAC (heterozigot) 